\title{
Determination of the Conditions for Agglomeration of Molybdenite Fines in the Presence of Kerosene Emulsion Through the Extended DVLO Theory
}

\author{
Antonio López Mendoza and Alicia Elizabeth Chàvez Guajardo
}

\begin{abstract}
The hydrophobic agglomeration of fine particles of molybdenite in the presence of kerosene emulsion, has been studied in this paper. The results obtained in the investigation as; zeta potential of kerosene emulsion( $\zeta_{\text {emulsion}}$ ), zeta potential of the molybdenite sample ( $\left.\zeta_{\mathrm{MoS} 2}\right)$, hydrophobicity of molybdenite represented by the contact angle $\left(\theta_{\mathrm{Mos} 2}\right)$ varying the $\mathrm{pH}$, were used to calculate the total potential energy $\left(\mathrm{U}_{\mathrm{T}}\right)$ through the extended DVLO theory. Diagram containing curves total potential energy vs. separation distance of the particles, indicate that increasing the $\mathrm{pH}$, also increases the energy barrier to overcome to achieve agglomeration and viceversa, which translates to a high probability of agglomeration in the $\mathrm{pH}$ range 5 to 8 , with greater effect as the $\mathrm{pH}$ is increased in the acidic region.
\end{abstract}

Index Terms - Extended DVLO theory, Fine particles Molybdenite; Hydrophobic agglomeration, Querosene emulsion.

\section{INTRODUCTION}

Molybdenum (Mo) also known as "Moly" is a metal that is gaining day by day, importance in the industrial world, because of their varied and growing applications. Being molybdenite $\left(\mathrm{MoS}_{2}\right)$, a mineral belonging to the class of sulfides and the main economic source of molybdenum.

For the recovery of molybdenite, their surface properties and the chemical nature of its crystal structure advantage, since because of these characteristics is a natural hydrophobic mineral and this makes the flotation process responds.

The crystal structure of molybdenite is hexagonal unit formed by a sheet of Mo atoms is sandwiched between two sheets $\mathrm{S}$ atoms, giving the three layered structure, between atoms of the crystalline structure two types of links, covalently associated between sulfur atoms and molybdenum (link S-Mo) and Van der Waals, between layers of S-Mo-S, which are established considerably weaker than the first.

The structural characteristics of molybdenite, result in the surface of the particles of the mineral, two different surfaces which can be found as: sites created by the breakdown of type Van der Waals bonds, which are called faces, and other sites created by the breaking of bonds S-Mo edges called, as the size reduces, the edge / face ratio increased and thus the

Published on January 15, 2021. Antonio López Mendoza

(e-mail: tony_lopez@uaz.edu.mx)

Alicia Elizabeth Chàvez Guajardo

(e-mail:achavezg@uaz.edu.mx) hydrophobicity of the molybdenite surfaces decreased, leading to the sharp falling of flotation efficiency [1].

On the other hand, forth flotation poorly responds to fine mineral particles, which is mainly due to the small mass of the particles and thus low probability of collision and adhesion of particles to air bubble, leading a low recovery of valuable minerals [2], [3]

Accordingly froth flotation is difficult to beneficiate molybdenite fines from ores. It is accepted that flocflotation, in which mineral fines are floated as hydrophobic agglomerates, is an effective process to improve the beneficiation of valuable minerals in fine particle size [4][7].

The central axis of the floc-flotation process is the hydrophobic agglomeration of fine mineral particles in aqueous solutions, which arises as a result of hydrophobic interaction between particles [8].

Hydrocarbons in the form of non-polar oil (such as kerosene and diesel), are commonly used to increase the hydrophobicity of molybdenite in flotation, by interacting with the face's organic reagents.

Hydrophobic agglomeration is proportional to the contact angle and therefore is a direct function of the hydrophobicity of the particle,

Hydrophobic agglomerates are characterized by compact structure and hydrophobic surfaces and have similar flotation behavior to normal particles in the same size.

There are three key parameters in hydrophobic agglomeration, namely particle hydrophobicity, kinetic energy input and nonpolar oil participation [9]-[13].

The more hydrophobic are the particles, the more powerful the hydrophobic agglomeration is, because hydrophobic attraction between particles in aqueous solutions closely correlates with the hydrophobicity of the particles. Kinetic energy input is realized bymechanical agitation (shear field) of fine particles suspensions, which gives the particles sufficient energy to overcome the potential energy barrier. Nonpolar oil droplets enhance hydrophobic agglomeration through the formation of oil bridges between hydrophobic particles and increasing particle hydrophobicity.

The hydrophobic agglomerates of molybdenite fines, which were prepared in the mixing tank with the stirring

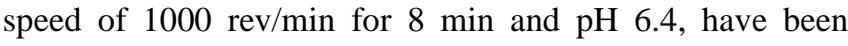
observed through SEM. It can be seen from that the molybdenite fines indeed formed agglomerates with the dimensions about $28 \times 40 \mu \mathrm{m}$. Also, the agglomerates were observed very compact [14]. 


\section{A. Theory}

The DLVO theory is named after it was developed in the 1940s [15], [16]. The theory describes the force between charged surfaces interacting through a liquid medium.

The DLVO theory explains the dispersion and agglomeration of particles. This theory describes the stability of colloids based on the interaction of two opposing forces acting on the particles. These two forces are electrostatic repulsion and attraction forces van der Waals. The DLVO theory states that the effect resulting from the interaction of these two forces determine whether the particles maintain a stable dispersion state or agglomerate.

According to classical DLVO theory, the energy barrier arises as a result of the interaction of the electrical double layer and van der Waals forces. The potential net interaction $\left(U_{T}\right)$ energy between two mass units separated by a distance " $h$ " between its surfaces is the sum of the potential energy of the electrical double layer $\left(U_{R}\right)$ and van der Waals, $\left(U_{A}\right)$ given by:

$$
U_{T}=U_{R}+U_{A}
$$

DLVO theory classical is not applicable to hydrophobic particles in aqueous suspension. It has been found that the hydrophobic force is once or twice in order of magnitude higher than the force considered in DLVO theory classical. Consequently, the hydrophobic interaction substantially reduces the energy barrier which favors aggregation efficiency.

DLVO theory extended expresses that the total potential of interaction energy to hydrophobic particles in aqueous suspension is:

$$
U_{T}=U_{R}+U_{A}+U_{H}
$$

where $U_{H}=$ is the potential energy due to structural forces, such as the hydrophobic attraction, magnetic attraction, repulsion by hydration or due to steric repulsion molecules adsorbed polymer [17], [18]. The curve obtained is called net interaction potential energy. If the net value is represented on the positive side, then it is repulsive, while if it is on the negative side, it is attractive. According to the extended DLVO theory, the curve of potential net interaction energy is also the result of considering the structural forces. The point of maximum energy in the repulsive part is the energy barrier which is the standard used to estimate the stability of the colloid. For a colloid achieve agglomerate, it is necessary to overcome the energy barrier which opposes the state of aggregation. When there is no energy barrier or the energy barrier is small, the agglomeration is carried over.

\section{B. Procedure for Calculation of the Total Interaction Potential Energy for the Studied System}

It was established in Equation 2, the total potential energy of interaction $\left(U_{T}\right)$ according to the extended DLVO theory it is the sum of: Potential interaction of van der Waals energy $\left(U_{A}\right)$ Potential interaction of the electrical double layer energy $\left(U_{R}\right)$ and hydrophobic interaction Potential energy $\left(U_{H}\right)$.

\section{Van der Waals interaction}

Universal attractive forces between atoms and molecules, known as Van der Waals force, also between macroscopic objects and play an important role in the interaction of colloid particles. Similar to the interaction of the electrical double layer manner, the Van der Waals force are expressed in terms of potential energy.

The potential energy of van der Waals interaction $\left(U_{A}\right)$ is calculated by [17]

$$
U_{A}=-\frac{A_{132} a_{1} a_{2}}{6 h\left(a_{1}+a_{2}\right)}
$$

where Hamaker constant $\left(\mathrm{A}_{132}\right)$ particle "1" and "2" interacting in a medium " 3 " is obtained by:

$$
\mathrm{A}_{132}=\left(\sqrt{A_{11}}-\sqrt{A_{33}}\right)\left(\sqrt{A_{22}}-\sqrt{A_{33}}\right)
$$

where $\mathrm{A}_{11}, \mathrm{~A}_{22}, \mathrm{~A}_{33}$ are the Hamaker constant materials 1,2 and 3 respectively.

\section{Electrical double layer interaction}

The interaction of the electrical double layer between charged colloids occurs due to the surface potential. The main factors that affect the interaction of the double layer are: 1) the surface charge and thus the zeta potential, 2) thickness of the electrical double layer $\left(\kappa^{-1}\right)$, and 3 ) interparticle distance $(\mathrm{h})$.

The interaction energy due to the electrical double layer $\left(U_{R}\right)$, was Obtained from the following expression [19].

$$
\begin{aligned}
& U_{R}=32 \pi \varepsilon_{0} \varepsilon a\left(\frac{k T}{e z}\right)^{2} \tanh \left(\frac{e z \zeta_{1}}{4 k T}\right) \tanh \left(\frac{e z \zeta_{2}}{4 k T}\right) \exp (-\kappa h) \\
& a=\frac{2 a_{1} a_{2}}{a_{1}+a_{2}}
\end{aligned}
$$

\section{Hidrophobic interaction}

It has been observed that hydrophobic attractive forces between hydrophobic surfaces in water obey an exponential relationship to their separation distance, generally expressed as:

$$
U_{H}=-f_{o} a h_{o} \exp \left(-\frac{h}{h_{o}}\right)
$$

According to Rabinovich and Derjaguin [20], the hydrophobic attractive force and the decay length depend on the hydrophobicity degree of the particle surfaces. When particle contact angles are not just equal to $100^{\circ}$, the expression must be revised by introducing a coefficient $\mathrm{k}_{1}$ that is only related to surface hydrophobicity. so, the potential energy of the hydrophobic interaction may be given by [21].

$$
U_{H}=-0.00251 a k_{1} h_{o} \exp \left(-\frac{h}{h_{o}}\right)
$$

where in the adjustment coefficient hydrophobicity $\left(\mathrm{k}_{1}\right)$ is obtained by:

$$
k_{1}=\frac{\exp \left(\frac{\theta}{100}\right)-1}{e-1}
$$


The description and values of all parameters used in the different formulas to calculate total interaction potential energy $\left(U_{T}\right)$, are presented in the appendice.

The aim of this research is to reach a better understanding of the process of hydrophobic agglomeration of molybdenite fines. Also, determine the conditions which may have Agglomeration through the values of the parameters obtained in the present investigation and the results generated by application the extended DLVO theory.

\section{EXPERIMENTAL}

\section{A. Materials}

\section{Mineral sample}

The molybdenite sample used in this work was originally collected from the molybdenum concentrate in the Nacozari concentration plant, located in Sonora State, Mexico. The concentrate was first subjected to a purification process which begins washing with $\mathrm{CS}_{2}$ to remove traces of chemical reagents. Subsequently, the sample was subjected to leaching with sodium cyanide $(\mathrm{NaCN})$ to remove higher copper content present. The next step was to float the Mo concentrate leached in a "Denver" flotation cell with a dilution of about 3: 1 (25\% solids) using only MIBC frother and deionized water, this product was two cleaned, in order to obtain the highest possible degree.

Once dry the Mo concentrate, obtained in the flotation; She washed a second time with carbon disulfide (CS $\left.{ }_{2}\right)$, following the procedure used above, to remove traces of froth.

Already obtained, the purity of the base sample for the research study, we proceed to obtain a sample fine particle size, the above is achieved by grinding the sample of $\mathrm{MoS}_{2}$ purified in a mill planetary type of discs with grinding surfaces based on tungsten carbide, control particle size is achieved using a Gilsonic microsizer Autosiever with a microcriba opening $10 \mu \mathrm{m}$, the above cycle is repeated until a size of $60 \%$ was obtained $-10 \mu \mathrm{m}$.

The sample and with the specified size, was subjected to sampling where portions of the order of 14 to $20 \mathrm{~g}$, which served to carry out various tests throughout the research were obtained.

\section{Reagents}

Hydrochloric acid $(\mathrm{HCl})$, potassium hydroxide $(\mathrm{KOH})$ such as pH modifiers. Fisher Chemicals kerosene; Sodium oleate, isopropyl sodium xanthate (NaIX) and potassium butyl xanthate (KBX) as surfactants; $\mathrm{KCl}$ as the electrolyte to control the ionic strength. The reagents used throughout the research were analytical grade except xanthates which were purified in the laboratory, according to the technique described in Song and Lu [22].

\section{Water used}

The water used in this study has the following characteristics: deionized water with a resistivity of 17 Megohm-cm, a brand BARNSTEAD mod deionizer was used. E-pure cartridges D4641 with ion exchange resins and activated carbon.

\section{B. Characterization of the Sample}

The sample, which represent the basis of this research were characterized by the following analytical studies:
Chemical analysis, X-ray Diffraction (XRD), Scanning Electron Microscopy (SEM).

\section{Chemical analysis}

By chemical analysis, the most significant elements present in the mineral sample were quantified. The analysis was carried out in an atomic absorption Spectrophotometer Perkin Elmer, model 3110, determined the following elements: $\mathrm{Mo}, \mathrm{Cu}, \mathrm{Fe}, \mathrm{SiO}_{2}$.

\section{X-Ray Diffraction (XRD)}

The analysis by X-ray diffraction, is an important tool to determine which are the phases minerals present in a sample. Based on principles of measurement, this analysis technique is used to see if there are mineral species above a concentration of 5\%. For which a Rigaku DMAX 2200 Model was used.

\section{Scanning Electronic Microscopy (SEM)}

Through this technique different photomicrographs of the sample were obtained for the identified of mineral phases; besides observing the morphology, size and distribution of the mineral particles that make up the samples. For which the Scanning Electron Microscope (SEM) brand JEOL Model JSM - 6610LV is used,

\section{Experimental Tests}

\section{Preparation of kerosene emulsion}

The emulsion was prepared by mixing of $99 \mathrm{ml}$ of water and $5 \times 10^{-5} \mathrm{~mol} / \mathrm{l}$ de $\mathrm{KBX}$ surfactant is performed for one minute, quickly added slowly kerosene $(1 \mathrm{ml})$, the mixture is stirred for five minutes with a four-blade stirrer, $450 \mathrm{rpm}$ turbine type. Later in the Ultraturrax equipment, the sample stirring vigorously at $8000 \mathrm{rpm}$ for 2.5 minutes, to finally obtain the emulsion, which has a light green color.

\section{Hydrophobic agglomeration}

The hydrophobic agglomeration of molybdenite fines in aqueous suspension was performed in a mixing tank of $8 \mathrm{~cm}$ inner diameter with six $1 \mathrm{~cm}$ width baffles, with the stirring speed of $800 \mathrm{rpm}$ for $5 \mathrm{~min}$ and $40 \mathrm{mg} / \mathrm{L}$ kerosene at $\mathrm{pH}=8$. Agitation was provided by an impeller located in the center of the stirring equipment; type turbine consists of four flat blades. The suspension of molybdenite fines was formed in the concentration of $1 \% \mathrm{wt}$, time after the $\mathrm{pH}$ is adjusted using hydrochloric acid or sodium hydroxide solution, kerosene emulsion was added during the conditioning. Hydrophobic agglomeration of molybdenite fines in aqueous suspensions was achieved after the conditioning.

3. Observation of hydrophobic agglomerates and kerosene emulsion

A Leica DMLP DC300 optical microscope equipped with digital camera was used to observe hydrophobic agglomerates in aqueous suspension and oil droplets in emulsions. The samples were prepared by dropping molybdenite suspension or kerosene emulsion on a glass plate, followed by putting a thin glass slide on the drop to fix the suspension or emulsion. During the observation, some of agglomerates or oil droplets were photographed. The molybdenite agglomerates were also observed by using a Philips Mod XL-30, electronic scanning microscope (SEM). The sample was prepared by dropping molybdenite suspension on a T-shape sample carrier, followed by drying naturally and then gold coating. The SEM images of the agglomerates were taken during the observation. 


\section{Zeta potential ( $\xi)$}

The zeta potential, for kerosene emulsion as for the sample of purified molybdenite was determined by varying the $\mathrm{pH}$, in a Zetàmetro, model Zeta probe-T6A, Colloidal Dynamics. The measurements were carried just under the following conditions: for kerosene emulsion at a concentration of $1 \%$ by volume, with $5 \times 10^{-5} \mathrm{~mol} / \mathrm{L}, \mathrm{KBX}$ and $2 \times 10^{-3} \mathrm{~mol} / \mathrm{L} \mathrm{KCl}$; whereas for molybdenite suspension to $2.8 \% \mathrm{wt}$, with $2 \times 10^{-3} \mathrm{~mol} / \mathrm{L}, \mathrm{KCl}$ was used; both prepared with deionized water. $\mathrm{KCl}$ was used as the supporting electrolyte, and $\mathrm{pH}$ adjusting $\mathrm{HCl}$ and $\mathrm{KOH}$ solutions were used.

5. Measurement of the contact angle $(\theta)$

The contact angle was determined on natural crystals of molybdenite from the "La Caridad" mine, located in the state of Sonora, Mexico. These crystals were mounted in a briquette, thereby making measurement in the crystal faces. The equipment used was the goniometer, Rame Hart NRL 100 - 00 which has attached a video camera, which captures the image of the air bubble on the glass surface molybdenite to monitor a PC.

\section{RESULTS AND DISCUSSION}

\section{A. Chemical Analysis}

The particle size distribution of the sample of molybdenite after purified and ground, indicated that $60 \%$ $10 \mu \mathrm{m}$, the Table I, presents the chemical composition of molybdenite used in this research, before and after purification.

TABLE I: CHEMICAL COMPOSITION

\begin{tabular}{lccccc}
\hline \multicolumn{7}{c}{ TABLE I: CHEMICAL COMPOSITION } \\
\cline { 2 - 6 } & $\mathrm{Mo}$ & $\mathrm{Cu}$ & $\mathrm{Fe}$ & $\mathrm{SiO}_{2}$ & $\mathrm{MoS}_{2}$ \\
\hline $\mathrm{MoS}_{2}$ non-purified & 49.7 & 1.26 & 3.41 & 3.67 & 82.8 \\
$\mathrm{MoS}_{2}$ purified & 56.4 & 0.41 & 0.56 & 1.62 & 94.0 \\
\hline
\end{tabular}

\section{B. X-Ray Diffraction (XRD)}

The XRD pattern of the sample is shown in Fig. 1. All of the peaks belonged to molybdenite. There was no impurity of over $5 \%$ grade in the sample.

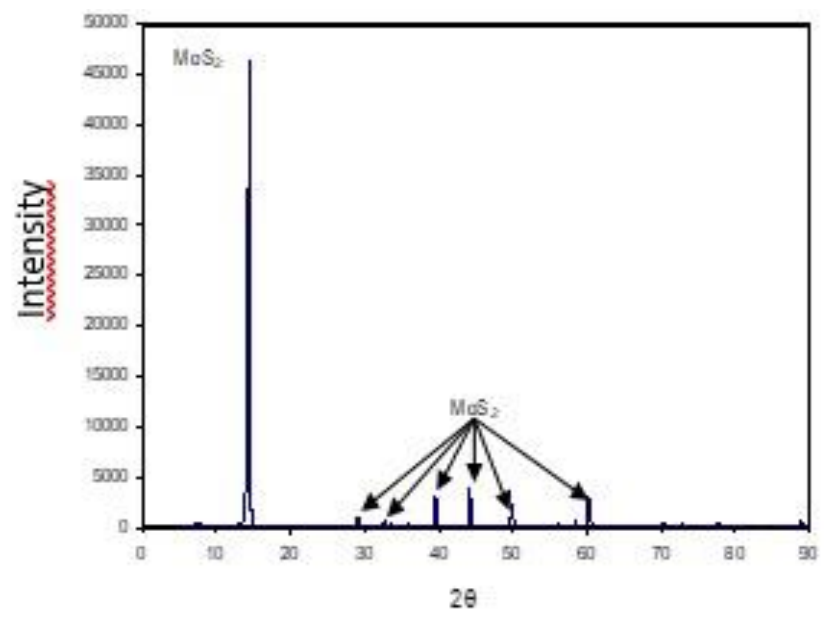

Fig. 1. XRD Pattern molybdenite
C. Observation of Molybdenite Sample, Hydrophobic Agglomerates and Kerosene Emulsion

The Fig. 2 shows the SEM images of sample under investigation, the Fig. 2a presents the state, shape, size, and distribution of particles molybdenite, while in Fig. 2b, type impurities containing sample is observed.

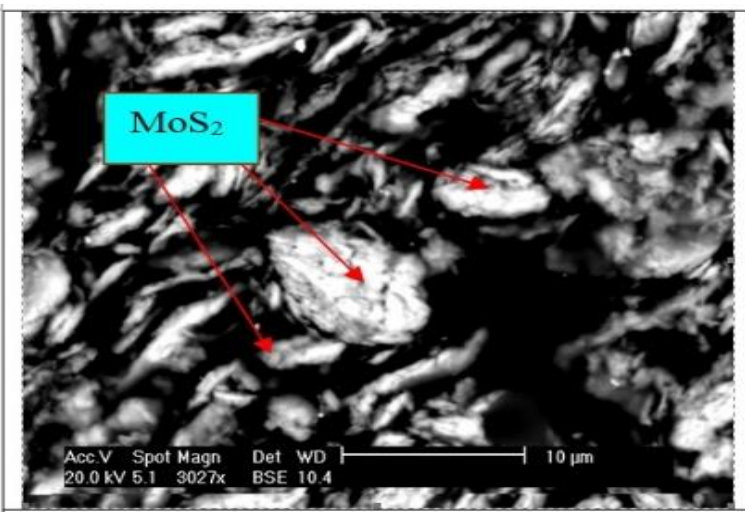

(a)

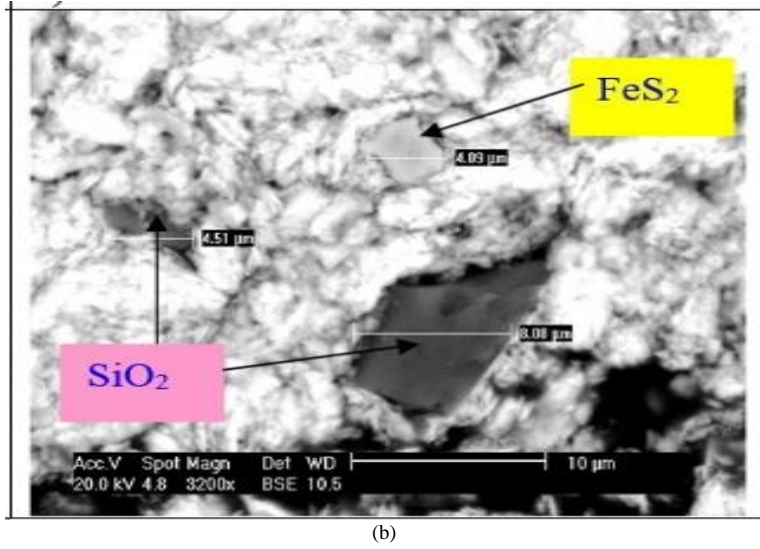

Fig. 2. SEM photomicrographs obtained. a) $\mathrm{MoS}_{2}$ particles different sizes; b) Impurities in the sample of molybdenite.

The hydrophobic agglomerates of molybdenite fines, have been observed through SEM and Optical Microscope in water. The SEM images are shown in Fig. 3-4. It can be seen from Fig. 3, that the molybdenite fines indeed formed agglomerates with the dimensions about $18 \times 21 \mu \mathrm{m}$ also in Fig. 4, hydrophobic agglomerates about $21 \times 41 \mu \mathrm{m}$ are observed [14], with compact structure most and larger size.

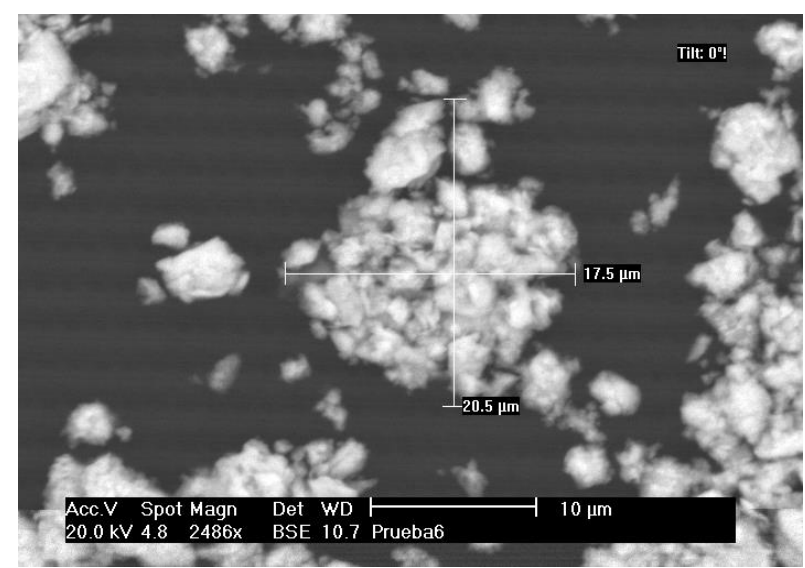

Fig. 3. SEM image of hydrophobic agglomerates; with $\mathrm{pH}=8$. 


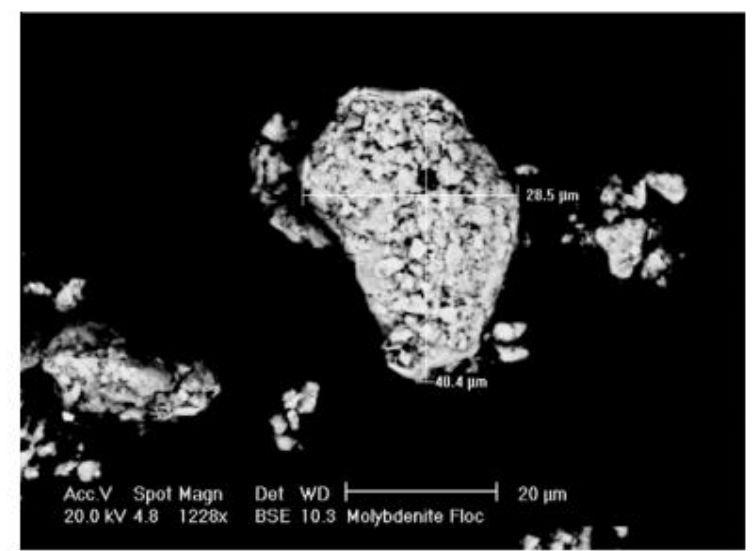

Fig. 4. SME image of hydrophobic agglomerates; with $\mathrm{pH}=6.4$ [14].

Fig. 5, 6 shows the optical microscopy images of hydrophobic agglomerates of molybdenite fines and the kerosene emulsion, agglomerates of different sizes is observed and most compact structure, the droplet size ranges from 29-67 $\mu \mathrm{m}$ although most of the droplets have a smaller size (30 to $40 \mu \mathrm{m}$ ) generating much more oil surfaces to contact molybdenite particles and then to enhance the hydrophobic agglomeration.

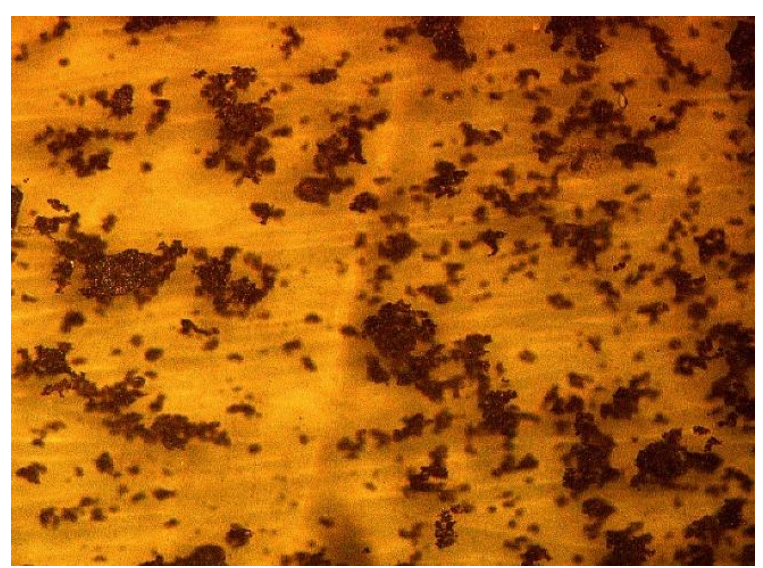

Fig. 5. Optical microscopy images of agglomerates.

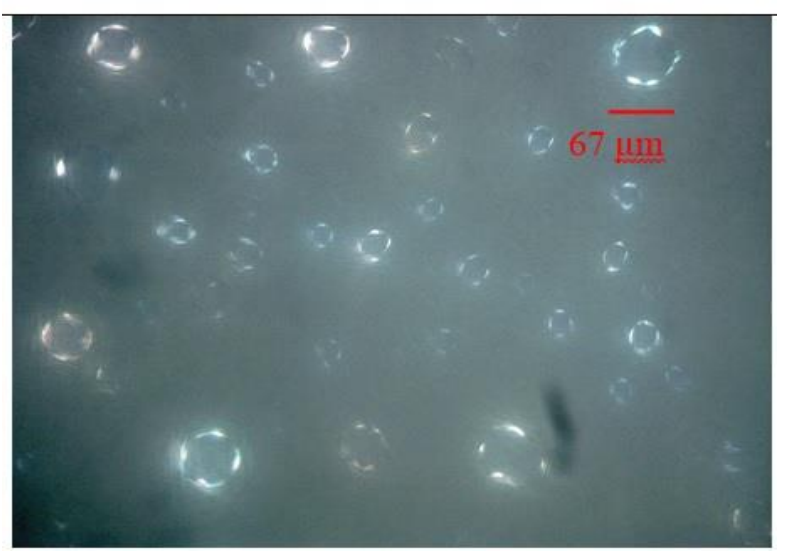

Fig. 6. Photomicrograph of droplets the kerosene emulsion.

\section{Zeta Potential (ל) for Purified Molybdenite and Kerosene Emulsion}

The variation of zeta potential $(\zeta)$ for kerosene emulsion and purified molybdenite with $\mathrm{pH}$, is presented in Fig. 7.

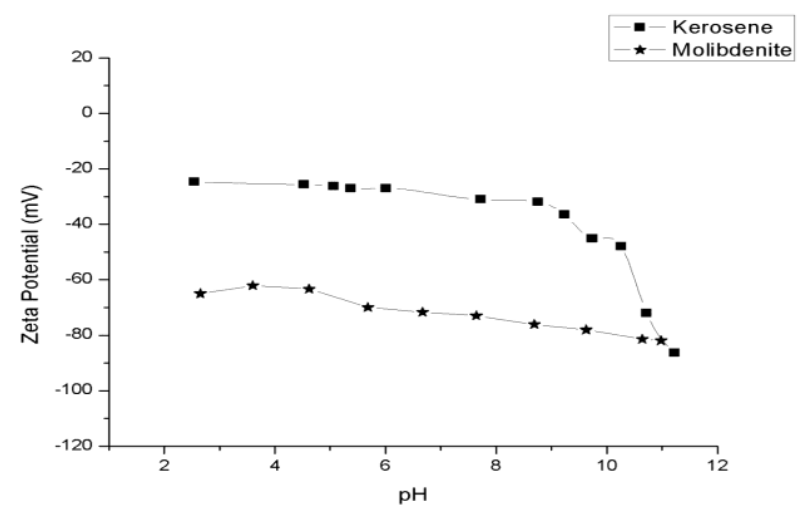

Fig. 7. Variation of the zeta potential $(\zeta)$ with $\mathrm{pH}$.

The zeta potential is always negative for molybdenite and kerosene emulsion for each $\mathrm{pH}$. The Fig. 7 shows that the zeta potential increases in absolute value to increase the value $\mathrm{pH}$; It is always negative over the range used.

\section{E. Contact angle measurement $(\theta)$}

The contact angle was determined on natural crystals of molybdenite from the "La Caridad" mine, located in the State of Sonora, Mexico. The study is to measure the $\mathrm{pH}$ effect on the contact angle, the results are shown in Fig. 8.

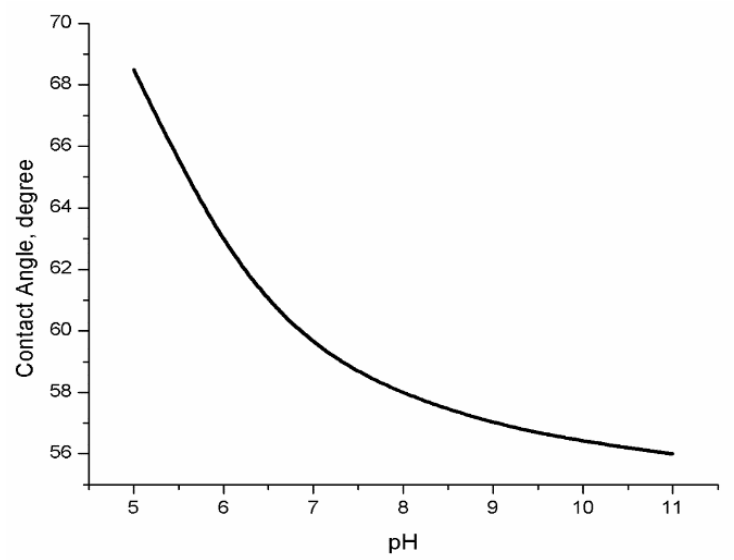

Fig. 8. Contact angle of the faces, molybdenite particles as a function of $\mathrm{pH}$.

The contact angle of the face of molybdenite particles in relation to Fig. 8 , varies $68.5^{\circ}$ at $56^{\circ}$, for a $\mathrm{pH}$ range of 5 to 11; implying a decrease in said angle with increasing $\mathrm{pH}$, this decrease is due to increased hydration layer from the edges adjacent to the face of the microcrystals.

F. Estimation of the Potential Total Interaction Energy $\left(U_{T}\right)$ between the Particles of Molybdenite and of Kerosene Emulsion Droplets

As an example, a run of calculation will be considering the values of the parameters obtained in the investigation and in the form specific for a $\mathrm{pH}=5$ and a distance between particles of $1 \mathrm{~nm}$.

Based on the equation 2, calculate each of the energies of interaction that are present in the system studied.

1. Energy van der Waals interaction $\left(U_{A}\right)$

The Hamaker constant of molibdenite fines and kerosene emulsion in water, will be used for the calculation of the van der Waals interaction potential energy.

Following Equation (4): 


$$
A_{132}=3.9226 \times 10^{-21} \mathrm{~J}
$$

Applying the value obtained in equation (3):

$$
U_{A}=-5.7800 \times 10^{-18} \mathrm{~J}
$$

2. Energy electrical double layer interaction $\left(U_{R}\right)$

Using the values of parameters contained in the appendix in addition to $\mathrm{pH} 5$ and $\mathrm{h}=1 \mathrm{~nm}$, by the computations follow Equation (5 - 6) the interaction energy is obtained.

$$
U_{R}=1.0943 \times 10^{-16} \mathrm{~J}
$$

\section{Energy hydrophobic interaction $\left(U_{H}\right)$}

Applying the equation 8 and 9 and returning to the appendix information is obtained:

$$
U_{H}=-1.4095 \times 10^{-16} \mathrm{~J}
$$

Thus, the total potential interaction energy $\left(U_{T}\right)$, to $\mathrm{pH}=5$ and $\mathrm{h}=1 \mathrm{~nm}$ equals to:

$$
\begin{aligned}
& U_{T}=U_{A}+U_{R}+U_{H} \\
& U_{T=-}-372.94 \times 10^{-19} \mathrm{~J}
\end{aligned}
$$

The Total potential interaction energy $\left(U_{T}\right)$ curve for the example, and computations for the range of $h=1$ to $60 \mathrm{~nm}$ is shown in the inset of Fig. 9.

Calculations based on the extended DVLO theory to determine the effect of $\mathrm{pH}$ on the probability of agglomeration of molybdenite fines through the height of the energy barrier to overcome is shown in Fig. 9.

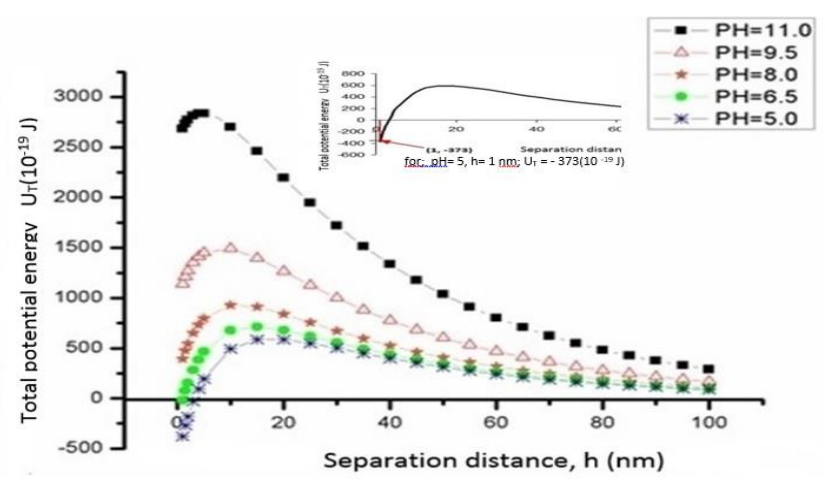

Fig. 9. Variation of total interaction potential energy $\left(U_{T}\right)$ with the separation distance $(\mathrm{h})$ for different $\mathrm{pH}$.

The height of the energy barrier in the system, significantly decreases with decreasing $\mathrm{pH}$, as shown by the energy - distance curves obtained in Fig. 9, which it means that in a $\mathrm{pH}$ range of weakly alkaline to acid $\mathrm{pH}(8-5)$ have a high probability of agglomeration because with decreasing $\mathrm{pH}$, the hydrophobic force (attractive force represented by the contact angle) is growing stronger in the energy balance for the system.

Based on the theoretical calculation using the extended DLVO theory, the agglomeration process is possible at $\mathrm{pH}=5$ to 8 , while with increasing its value in the alkaline region the probability of agglomeration is reduced consistently and to $\mathrm{pH}=11$ the probability is practically zero based on Fig. 9, as shows that the height of the energy barrier to be overcome is the highest and is completely in the repulsion zone.

\section{CONCLUSIONS}

*Experimental development confirms the agglomeration of the molybdenite fines in the presence of kerosene emulsion.

*Theoretical calculation through the extended DLVO theory, shows that the Energy Hydrophobic Interaction $\left(U_{T}\right)$ increases, as the contact angle $(\theta)$ is increased to decrease the $\mathrm{pH}$; and it is of a larger magnitude that for the electric double layer, to a weighted value of the Zeta potential $(\zeta)$; under these conditions there is a high probability that the hydrophobic agglomeration occurs.

*Based on the theoretical calculation and supported by the results obtained in this investigation and existing in the literature on the evaluation system studied, are generally proposed that the conditions which may have agglomeration are: Slightly alkaline to acid $\mathrm{pH}(8-5)$, where prevailing low values of zeta potential and high contact angle more preferably to advance the acid region.

Thus, the present research of Hydrophobic agglomeration of molybdenite fines in the presence of kerosene emulsion

\begin{tabular}{|c|c|c|c|}
\hline Parameter name & symbol & Value & Units \\
\hline $\begin{array}{l}\text { Separation distance between } \\
\text { particles }\end{array}$ & $\mathrm{h}$ & 1 a $100\left(\times 10^{-9}\right)$ & $\mathrm{nm}(\mathrm{m})$ \\
\hline $\begin{array}{c}\text { Adjustment coefficient degree of } \\
\text { hydrophobicity }\end{array}$ & $\mathrm{k}_{1}$ & Equation (9) & \\
\hline $\begin{array}{l}\text { Reduction in length, in the } \\
\text { distance }\end{array}$ & $\mathrm{h}_{0}$ & $12.2\left(\times 10^{-9}\right) \mathrm{k}_{1}$ & $\mathrm{~nm}(\mathrm{~m})$ \\
\hline Permittivity of water & $\varepsilon$ & 78.55 & \\
\hline Permittivity vacuum & $\varepsilon_{0}$ & $8.85 \times 10^{-12}$ & $\begin{array}{l}\mathrm{C}^{2} \cdot \mathrm{N}^{-} \\
{ }^{1} \cdot \mathrm{m}^{-2}\end{array}$ \\
\hline Product permittivity & $\varepsilon_{\mathrm{r}}$ & $6.95 \times 10^{-10}$ & $\begin{array}{l}\mathrm{C}^{2} \cdot \mathrm{N}^{-} \\
{ }^{1} \cdot \mathrm{m}^{-2}\end{array}$ \\
\hline absolute temperature & $\mathrm{T}$ & 298 & $\mathrm{~K}$ \\
\hline constant universal gases & $\mathrm{R}$ & 8.314 & $\mathrm{~J}^{\mathrm{mol}}{ }_{1}^{-1} \mathrm{~K}$ \\
\hline Ions Valencia & $\mathrm{z}$ & 1 & \\
\hline Faraday constant & $\mathrm{F}$ & 96,487 & C. $\mathrm{mol}^{-1}$ \\
\hline Debye-Huckel parameter & $\kappa$ & $0.02546 \times 10^{9}$ & $\mathrm{~m}^{-1}$ \\
\hline Double layer thickness & $\kappa^{-1}$ & $39.277 \times 10^{-9}$ & $\mathrm{~m}$ \\
\hline Boltzmann constant & $k_{\mathrm{B}}$ & $1.38 \times 10^{-23}$ & $\mathrm{~J} . \mathrm{K}^{-1}$ \\
\hline Electron charge & $\mathrm{e}$ & $1.60 \times 10^{-19}$ & $\mathrm{C}$ \\
\hline Particle radius molybdenite & $\mathrm{a}_{1}$ & $14 \times 10^{-6}$ & $\mathrm{~m}$ \\
\hline $\begin{array}{c}\text { Radio drop nonpolar oil } \\
\text { emulsion }\end{array}$ & $\mathrm{a}_{2}$ & $24 \times 10^{-6}$ & $\mathrm{~m}$ \\
\hline $\begin{array}{l}\text { effective radius of the particle } \\
\text { (considering the sizes a1 and a } 2 \text { ) }\end{array}$ & a & Equation (6) & $\mathrm{m}$ \\
\hline $\begin{array}{l}\text { zeta potential molibdenite of a } \\
\text { certain } \mathrm{pH} \text { value }\end{array}$ & $\zeta_{1}$ & -0.064 & V \\
\hline $\begin{array}{l}\text { zeta potential of the emulsion at } \\
\text { certain } \mathrm{pH} \text { value }\end{array}$ & $\zeta_{2}$ & -0.026 & V \\
\hline $\begin{array}{c}\text { Hamaker constant of } \\
\text { molybdenite }\end{array}$ & $\mathrm{A}_{11}$ & $9.1 \times 10^{-20}$ & $\mathrm{~J}$ \\
\hline Hamaker constant drop emulsion & $\mathrm{A}_{22}$ & $7.5 \times 10^{-20}$ & $\mathrm{~J}$ \\
\hline Hamaker constant water & $\mathrm{A}_{33}$ & $5.0 \times 10^{-20}$ & $\mathrm{~J}$ \\
\hline Hamaker constant water & $\mathrm{A}_{132}$ & Equation (4) & $\mathrm{J}$ \\
\hline
\end{tabular}
can be explained considering the interaction forces present in the investigated system by means of the extended DVLO theory.

\section{APPENDIX}

DESCRIPTION OF THE PARAMETERS AND VALUES USED IN DETERMINING THE 


\section{ACKNOWLEDGMENT}

National Council of Science and Technology (Conacyt) and Autonomous University of Zacatecas (UAZ). Universidad Autónoma de San Luis Potosí (UASLP) through Institutional Doctor of Engineering and Materials Science (DICIM) and Simulation Laboratory of the Institute of Metallurgy, thanks for make this work possible.

\section{REFERENCES}

[1] S. Chander., D.W. Fuerstenau., On the natural flotability of molybdenite, Trans.Am. Inst. Min. Metall. Eng. 252(1972), 62-69.

[2] N. Arbiter., Problems in sulfide ore processing, in: P. Somasundaran, N. Arbiter (Eds.), Beneficiation of Mineral Fines Problem and Research Needs, AIME, Ann Arbor, (1979) pp. 139-152.

[3] D.W. Fuerstenau. S. Chander., A. M. Abouzeid, The recovery of fine particles by physical separation methods, in: P. Somasundaran, N. Arbiter (Eds.) Beneficiation of Mineral Fines Problems and Research Needs, AIME, Ann Arbor, 1979, pp. 3-59.

[4] R. D. Coleman., B. D. Sparks., A. Majid, F.N. Toll, Agglomerationflotation: recovery of hydrophobic components from oil sands fine tailings, Fuel 74 (1995), 1156-1161.

[5] T.L. Koh P., L. J. Warren, flotation of flocs of ultrafine scheelite, Trans. IMM Sect. C 86(1977) - C94-C95.

[6] S. Song, A. Lopez V., J. I. Reyes, B., C. Lara. V., Flocflotation of galena and sphalerite fines, Min. Eng. 14(2001), 87-98.

[7] S. Song, O. Trass., Floc-flotation of the Prince coal with simultaneous grinding and hydrophobic flocculation in a szego mill, Fuel 76 (1977), 839-844.

[8] S. Song., S. Lu., Hydrophobic flocculation of fine hematite, siderite, and rhodochrositte particles in aqueous solution, J. Coll oid Interfacial. Sci. 166 (1994), 35-42.

[9] Y. Cebeci., Investigation of kinetics of agglomerate growth in oil agglomeration process, Fuel 82 (2003), 1645-1651.

[10] S. Duzyola., A. Ozkan., Role of hydrophobicity and surface tension on shear flocculation and oil agglomeration of magnesite, Sep. Purif. Technol. 72(2010), 7-12.

[11] S. Duzyola., A. Ozkan., Correlation of flocculation and agglomeration of dolomite with its wettability, Sep. Sci. Technol. 46, 876881.Elsevier, New York (2011). p. 216.

[12] S. Song., A. Lopez-V., J.L. Reyes-B., H. I. Bermejo-Perez, Hydrophobic flocculation of sphalerite fines in aqueous solution induced by ethyl and amyl xanthates, Colloids Surf. A 181(2001)., $159-169$.

[13] L. Warren., Shear flocculation, in: J.S. Laskowski, J. Ralston (Eds.), Colloid Chemistry in Mineral Processing, Elsevier, Amsterdam (1992), pp.309-329.

[14] S. Song, X. Zhang., B. Yang., A. Lopez M., Flotation of molybdenite fines as hydrophobic agglomerates., Separation and Purification Technology., 98 (2012) 451-455.

[15] B.V. Derjaguin., L. Landau., Theory of the stability of strongly charged lyophobic sols and of the adhesion of strongly charged particles in solutions ofelectrolytes. (1941), Acta Phys. Chim. 14, 633.

[16] E. J. Verwey. W., J. T. Overbeek. G., Theory of the Stability of Lyophobic Colloids (1948)

[17] C.P. Hiemenz, C.P., R. Rajagopalan., Principles of Colloid and Surface Chemistry, Third Edition, Marcel Dekker Inc., New York (1997), pp. 499-527.

[18] P. Gast A., W. Adamson. A., Physical Chemistry of Surfaces, Wiley \& Sons, $6^{\mathrm{a}}$ ed (1997), USA.

[19] J. Gregory., Interaction of unequal double layers at constant charge., Journal of Colloid and Interface Sci. vol.51, issue 1 (1975), 44-51.

[20] Y.I. Robinovich., and B.V. Derjaguin., Colloid Surf (1988), 30,243.

[21] S. Song., A. Lopez V., Computational studies on Interaction between air bubbles and Hydrophobic Mineral Particles Covered by Nonpolar Oil., Journal of Colloid and Interface Science 212 (1999), 42-48.

[22] S. Song, S., Lu, S., "Theory and applications of hydrophobic flocculation technology", XIX International Mineral Processing Congress (Ed. Massacci P.), Vol. C5, Proceedings of Elsevier Amsterdam (2000), pp.31-38.

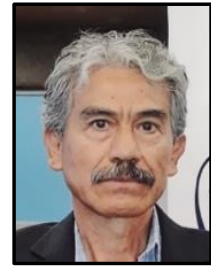

Ph.D. Antonio Lòpez Mendoza, Research Professor full-time of the Academic Unit of Earth Sciences of the Autonomic University of Zacatecas 1987-present, and responsible for the career of metallurgist mining engineer (2016 to 2020), I obtained the doctorate in sciences in the Institutional Doctorate of Engineering and Materials Science, UASLP; I received a Master's Degree in science from the Metallurgy Institute of the University's Engineering Faculty, UASLP, and a degree in Metallurgical Engineering from the National Polytechnic Institute of Mexico: publications of scientific articles, extensive memoirs and participation as a lecturer in congresses of mining.

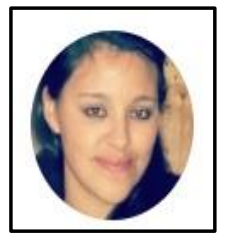

Ph. D. Alicia Elizabeth Chávez-Guajardo currently works at the Unidad Académica de Ciencias de la Tierra, Autonomous University of Zacatecas. Alicia does research in Biotechnology, Environmenta Engineering and Chemical Engineering. Their most recent publication is 'Electrospun polystyrene(emeraldine base) mats as high-performance materials for dye removal from aqueous media' 